Journal of Environmental
ISSN: $2525-815 \mathrm{X}$

\title{
Estudo comparativo da biologia floral de variedades comerciais de melancieira em cultivo orgânico
}

\section{Comparative study of floral biology of commercial watermelon varieties in organic farming}

Josemar da Silva Júnior ${ }^{\mathrm{a}}$, Thiago Francisco de Souza Carneiro Neto ${ }^{\mathrm{a}}$, Carine Feitosa Xavier ${ }^{\mathrm{a}}$, Tiago Nunes da Silva ${ }^{\text {a }}$, Diego Lima Coutinho ${ }^{\text {a }}$, Pedro Henrique Carvalho Ribeiro ${ }^{\text {, }}$ Leangleison Santos de Souza $^{\mathrm{a}}$, Kátia Maria Medeiros de Siqueira ${ }^{\mathrm{a}}$

a Universidade do Estado da Bahia-UNEB, Departamento de Tecnologia e Ciências Sociais, Campus III. Avenida Edgar Chastinet, s/n, São Geraldo, Juazeiro, Bahia, Brasil. CEP: 48900-000. E-mail: josemars929@gmail.com, tcarneiro@uneb.br, carinexavier@outlook.com, tiagonunes.silva@gmail.com, diegocoutinho.150@gmail.com, pedroohcr@gmail.com, leangleison2012@hotmail.com, katiauneb@yahoo.com.br.

\begin{tabular}{l}
\hline A R T I C L E I N F O \\
\hline Recebido 03 Abr 2020 \\
Aceito 14 Jan 2021 \\
Publicado 11 Mar 2021
\end{tabular}

\begin{abstract}
A B S T R A C T
Watermelon (Citrullus lanatus) is an economically important cucurbit for the Brazil Northeast region, considered the largest producer in the country. The studies related to floral biology are very important for the production and quality of commercial fruits. The study aimed to compare floral biology in four varieties of watermelon under irrigated organic cultivation, evaluating the flowering period, anthesis and floral senescence, the percentage of pollen viability, stigmatic receptivity, nectar production, and fruit production. We assessed the varieties of watermelon 'Charleston Gray', 'Congo', 'Crimson Select', 'BRS Soleil'. The experiment was carried out in an organic system from January to June 2018, in the experimental area of DTCS - CAMPUS III - UNEB, in Juazeiro - Bahia. During the experiment, the plants were watered by drip and under organic cultivation. The BRS Soleil and Charleston varieties had 31 days flowering period, 'Congo' for about 28 days, 'Crimson Select' 23 days. All varieties had high pollen viability, the stigmatic receptivity test recorded $100 \%$ for all varieties, and male flowers exhibited higher production of nectar volume. The highest registered sex ratio was in 'Congo' variety. Keywords: Citrullus lanatus, flowering, sex ratio, pollen viability.
\end{abstract}

\footnotetext{
R E S U M O

A melancia (Citrullus lanatus) é uma cucurbitácea de importância econômica para a região nordeste, considerada a maior produtora do país. Os estudos relacionados a biologia floral sobre, são muito importantes para a produção e qualidade de frutos comerciais. $\mathrm{O}$ estudo objetivou comparar a biologia floral em quatro variedades de melancieira, sob cultivo orgânico irrigado, avaliando o período de floração, a antese e senescência floral, o percentual de viabilidade polínica, receptividade estigmática, a produção de néctar e produção de frutos. Foram avaliadas as variedades de melancieira 'Charleston Gray', 'Congo', 'Crimson Select' e 'BRS Soleil'. O experimento foi conduzido em sistema orgânico durante o período de janeiro a junho de 2018, na área experimental do DTCS - CAMPUS III - UNEB, em Juazeiro Bahia. As variedades BRS Soleil e Charleston apresentaram período de floração de 31 dias, a 'Congo' de 28, a 'Crimson Select' de 23 dias. Todas as variedades obtiveram alta viabilidade polínica, o teste de receptividade do estigmática registrou $100 \%$ para todos as variedades, as flores masculinas exibiram maior produção do volume de néctar. A maior razão sexual registrada foi registrada para a variedade Congo.

Palavras-Chave: Citrullus lanatus, floração, razão sexual, viabilidade polínica.
} 


\section{Introdução}

A melancieira [Citrullus lanatus (Thunb.)

Matsum. \& Nakai] pertence à família Cucurbitaceae, destacando-se nas dicotiledôneas com distribuição nas regiões tropicais, constituída por mais de 750 espécies e mais de 100 gêneros (Ajuru \& Okoli, 2013).

Em 2014, a China figurava como o maior produtor mundial de melancia $(66,4 \%)$, seguida pela Turquia $(3,8 \%)$, pelo Irã $(3,6 \%)$ e pelo Brasil $(2,0 \%)$, alcançando juntos, aproximadamente, $76 \%$ do total produzido no mundo (Fao, 2016).

De acordo com os últimos dados oficiais, no Brasil, apesar do Rio Grande do Sul liderar como maior produtor nacional, a região Nordeste lidera o ranking de área plantada e de produção, com 28.989 hectares e produção de 538.094 toneladas, sendo os estados da Bahia e do Rio Grande do Norte os maiores produtores nesta região (Ibge, 2016).

As estratégias reprodutivas e os recursos disponíveis na flor são características que embasam estudos que objetivam o melhoramento genético e o rendimento de frutos de cultivares comerciais (Cobra et al., 2017), principalmente devido à atratividade para os polinizadores, constituindo-se um fator importante para uma maior produtividade da cultura. Corroborando o exposto, um estudo realizado no México registrou perdas siginificativas na produção de frutos de melancia, em consequência do atraso na introdução de colmeias de Apis mellifera L. no cultivo, e consequente atraso na polinização, principalmente em função do padrão de floração (Reyes-Carrillo, Cano-Rios \& Camberos, 2009).

Desse modo, para uma polinização bemsucedida, devem ser consideradas atributos florais como viabilidade do pólen, receptividade ao estigma, volume do néctar, quantidade do grão de pólen, tamanho, cor (Cobra et al., 2017; Kiill et al., 2014). A variação desses atributos influenciam na preferência de visitação entre variedades e entre híbridos de curcubitáceas pelos polinizadores (Kiill et al., 2014).

Ressalta-se a importância da agricultura orgânica na preservação dos polinizadores. No Vale do Submédio São Francisco, região considerada como maior polo de fruticultura irrigada do País, utiliza-se práticas agrícolas convencionais que inclui o uso de agroquímicos, aumentando a possibilidade de envenenamento de visitantes florais e, recentemente, a perda de polinizadores e serviços de polinização tem levado à crescente preocupação (Potts et al., 2010; 2016).

Diante do exposto, visando embasar estudos de melhoramento vegetal e manejo cultural na cultura da melancieira, o estudo objetivou comparar a biologia floral de quatro variedades de melancieira, sob cultivo orgânico.

\section{Material e Métodos}

$\mathrm{O}$ experimento foi conduzido no período de janeiro a junho de 2018, em área experimental do Departamento de Tecnologia e Ciências Sociais - DTCS, do Campus III - UNEB (09²5'43.6" S, 40³2'14" W, $384 \mathrm{~m}$ acima do nível do mar), em Juazeiro/BA. O clima característico do município é semiárido - BSwh', segundo a classificação de Köppen (quente e seco), com precipitação média anual de $542 \mathrm{~mm}$ (Embrapa, 2015).

$\mathrm{O}$ solo presente na área experimental foi classificado como neossolo flúvico e a análise química apresentou as seguintes características químicas na profundidade de 0 a $20 \mathrm{~cm}$ : $\mathrm{pH}$ (água) $=6,5 ; \mathrm{CE}=0,57 \mathrm{dS} \mathrm{m}^{-1} ; \mathrm{P}=68,65 \mathrm{mg} \mathrm{dm}^{-3} ; \mathrm{K}=$ $0,72 \mathrm{cmolc} \mathrm{dm}^{-3} ; \mathrm{Ca}=7,3 \mathrm{cmolc} \mathrm{dm}^{-3} ; \mathrm{Mg}=1,9$ cmolc dm ${ }^{-3} ; \mathrm{Na}=0,15 \mathrm{cmolc} \mathrm{dm}^{-3} ; \mathrm{Al}=0,00$ cmolc $\mathrm{dm}^{-3} ; \mathrm{H}+\mathrm{Al}=0,99 \mathrm{cmolc} \mathrm{dm}^{-3} ; \mathrm{MO}=20,0 \mathrm{~g} \mathrm{~kg}^{-1}$. As adubações seguiram as recomendações para a cultura.

Foram utilizadas quatro variedades de melancieira (C. lanatus) comerciais, a 'Charleston Gray', 'Congo', 'BRS Soleil' e 'Crimson Select'. As mudas foram preparadas em bandejas com substrato comercial em casa de vegetação, sendo transplantadas quando emitiram a segunda folha verdadeira, dispostas em um espaçamento de $3 \mathrm{~m}$ entre linhas e $1 \mathrm{~m}$ entre as plantas.

A área foi dividida em 15 blocos casualizados, com 4 tratamentos (variedades de melancieira); a unidade experimental foi constituída de 10 plantas, totalizando 150 plantas por variedade, perfazendo um total de 600 plantas no experimento. Durante todo o cultivo, as plantas foram mantidas com irrigação localizada por gotejamento e sob cultivo orgânico. No início da floração selecionou-se, aleatoriamente, 14 plantas por variedade, sendo uma planta de cada variedade por bloco. Estas plantas foram marcadas com fita colorida e acompanhadas durante todo o período de emissão de flores, para registro (diário) do número de flores por tipo floral (masculina, feminina e hermafrodita). Desse modo, obteve-se a relação sexual, determinou-se o período de floração por tipo floral e a relação da frutificação com a emissão de flores durante a floração.

$\mathrm{Na}$ determinação do horário da antese e da senescência floral foram selecionadas 10 flores, sendo cinco masculinas e cinco femininas, de cada variedade, totalizando 20 flores por tipo floral, acompanhadas desde o início da abertura até a sua senescência

Para a receptividade estigmática, ensacouse, no dia anterior à antese, 12 flores femininas de 
cada variedade e testou-se em diferentes horários, nos intervalos de $8 \mathrm{~h}, 11 \mathrm{~h}$ e $14 \mathrm{~h}$, com a aplicação de gotas de peróxido de hidrogênio $\left(\mathrm{H}_{2} \mathrm{O}_{2}\right)$ a $10 \mathrm{vol}$ sobre o estigma e verificando se havia formação de bolhas, caracterizando-o receptivo (Zeisler, 1938).

Para determinar o percentual de viabilidade polínica, ensacou-se, em pré-antese, as flores masculinas, visando evitar a contaminação do pólen de outras plantas pelos visitantes florais. Foram testados dois métodos colorimétricos, um com carmim acético a $2 \%$ e outro com lugol a $1 \%$. O carmim acético cora os grãos de pólen viáveis com rosa forte, devido a afinidade com DNA e RNA, enquanto os inviáveis apresentam-se transparentes. O iodo presente no lugol reage com $o$ amido dos grãos, conferindo tonalidades escuras de marrom; devido à ausência de amido nos grãos estéreis, não há reação química, mostrando-se mais claros ou transparentes (Pagliarini \& Pozzobon, 2004). Dessa forma, para cada coloração foram utilizadas nove flores por variedade, com três flores por horário, nos intervalos de $8 \mathrm{~h}, 11 \mathrm{~h}$ e $14 \mathrm{~h}$. Nos respectivos horários, as flores foram coletadas e levadas ao laboratório para a extração das anteras, utilizando pinça. Depositou-se as anteras de cada flor em uma lâmina para microscopia, onde foram maceradas e, posteriormente, coradas. Sob microscópio, procedeu-se a contagem de 300 grãos de pólen por lâmina, sendo classificados, dependendo da coloração, em viáveis (quando corados) e inviáveis (quando não corados); os resultados foram expressos em percentagem.

$\mathrm{O}$ volume de néctar foi quantificado pela técnica do ponto, segundo Kearns \& Inouye (1993). Foram ensacados 20 botões florais masculino e 15 botões florais feminino aleatórios para cada variedade, e cinco flores masculinas, três femininas por horário, nos intervalos de $8 \mathrm{~h}, 11 \mathrm{~h}$, 14 h e 17 h. Após a antese, as flores foram coletadas e obtido o néctar usando papel de filtro específico.

Os dados foram submetidos à análise de variância e as médias comparadas pelo teste de
Tukey a 5\% de probabilidade, utilizando o programa Sisvar v. 5.6 (Ferreira, 2011).

\section{Resultados e Discussão}

$\mathrm{O}$ teste de receptividade estigmática utilizando peróxido de hidrogênio, registrou $100 \%$ de receptividade em todos os horários avaliados para todas as variedades. Semelhante ao descrito por Alencar (2013), o estigma permaneceu receptível enquanto as flores estiverem abertas. Estes resultados indicam que durante todo o período de abertura das flores estas estão aptas a receberem o pólen e assim assegurar a frutificação.

O horário de antese ocorreu no período de 06h00min - 6h30min, abrindo-se nas primeiras horas de insolação e permanecendo aberta durante a manhã, chegando a senescer no intervalo de 13h00min - 14h00min.

A temperatura registrada próxima ao solo foi de $26,1^{\circ} \mathrm{C}$ no horário de $6 \mathrm{~h} 00 \mathrm{~min}$, com a umidade relativa do ar aproximadamente de $67 \%$, sendo o pico de $54,9^{\circ} \mathrm{C}$ às $11 \mathrm{~h} 00 \mathrm{~min}$, com $18 \%$ de umidade. Segundo Free (1993), em regiões de clima mais quente, a antese e a senescência das flores tendem a ser mais precoces. Resultados não muito distintos foram registrados em estudo realizado na região de Teresina-PI, onde a abertura iniciou- se às 5 h30min e cerca de 10 minutos após todas as flores estarem abertas; o fechamento iniciou-se às $10 \mathrm{~h} 15 \mathrm{~min}$, com fechamento total entre $10 \mathrm{~h} 30 \mathrm{~min}$ e $11 \mathrm{~h} 00 \mathrm{~min}$ do mesmo dia (Alencar, 2013).

Como mostrado na Figura 1, nas quatro variedades avaliadas registrou-se, inicialmente, a emissão de flores masculinas. Ainda, seu número permaneceu maior que as flores femininas durante todo o período de floração. Esse padrão também foi observado em outros estudos com outras variedades de melancieira no semiárido (Duarte et al., 2015) e também registrado em meloeiro, sugerindo ser uma característica das cucurbitáceas (Siqueira et al., 2011). 


\section{Crimson}

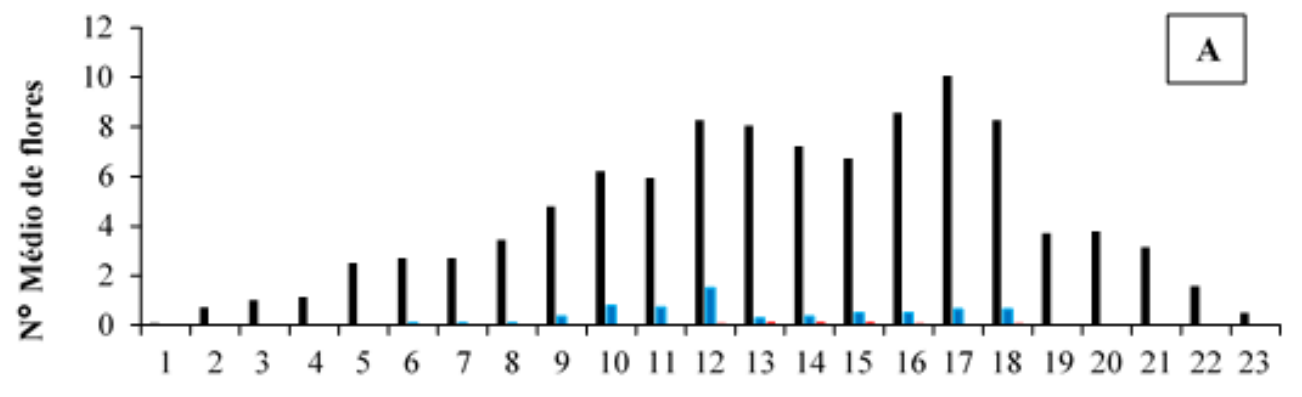

Dia

- Masculina $=$ Feminina $\quad$ Hermafrodita

Charleston

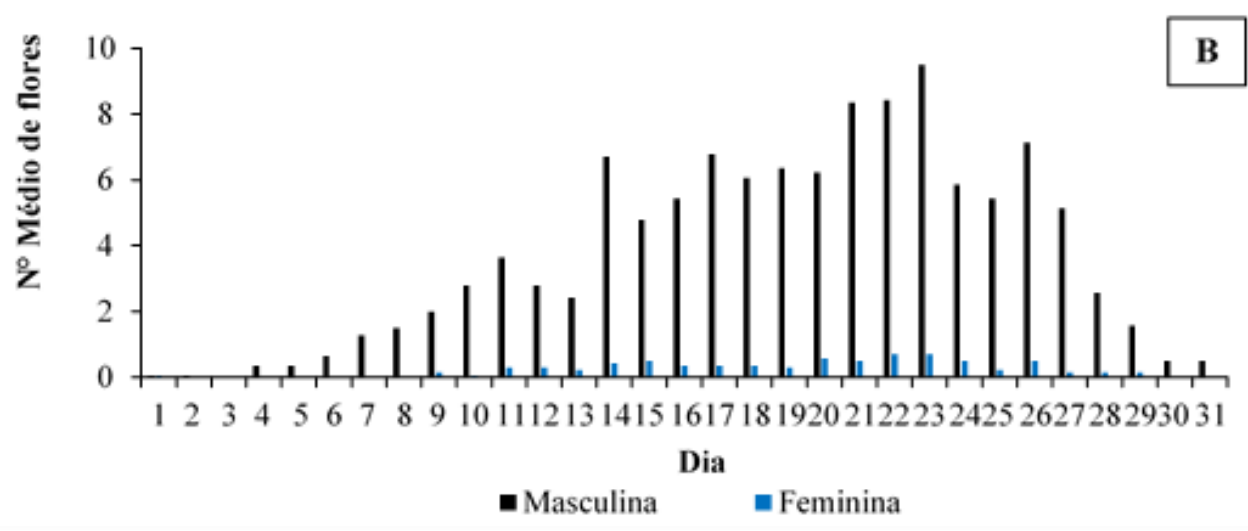

\section{Congo}
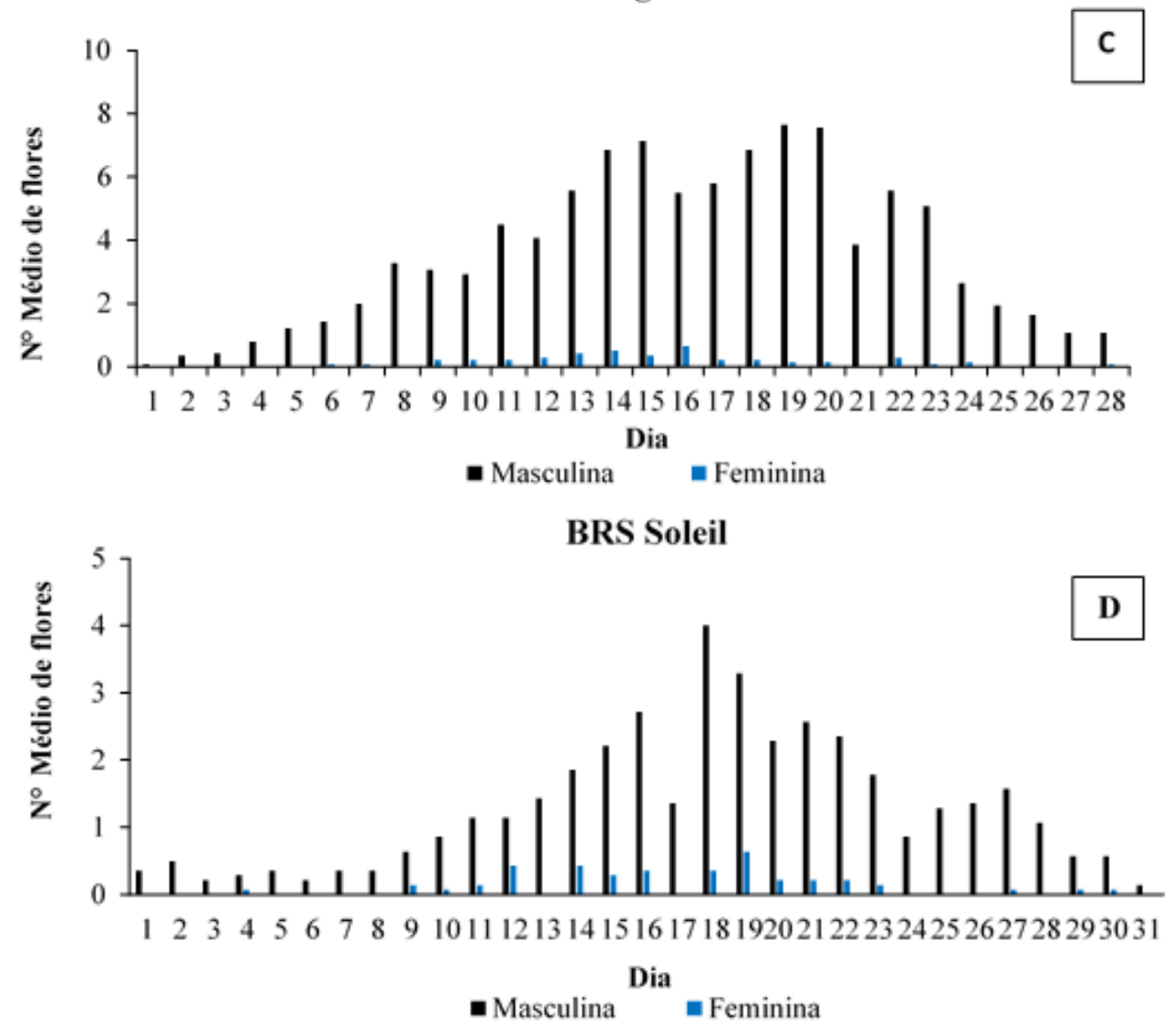

Figura 1. Período de floração em variedades de melancieira (Citrullus lanatus), em cultivo orgânico irrigado, Juazeiro-BA, em 2018. A = Crimson; B = Charleston; C = Congo; D = BRS Soleil. Fonte: Silva-Júnior et al. (2020). 
O início da floração foi com oito dias após transplantio (DAT) das mudas para o campo com flores da variedade BRS Soleil (Figura 1). Essa característica de precocidade foi registrada também por Ramos, Dias \& Aragão (2009) em outra variedade de melancia similar. A precocidade de 'BRS Soleil' é uma característica agronômica interessante, pois possibilita retorno econômico mais rápido, além da redução de custos por utilizar menos insumos e mão-de-obra, visto que ficará menos tempo em campo (Souza \& Dias, 2011).

Com 12 DAT, a 'Charleston' emitiu as suas primeiras flores masculinas, aos 15 DAP, a 'Congo' registra as suas primeiras flores masculinas e, por último, a 'Crimson Select' com 17 DAT.

Para ao pico floral, nas flores masculinas foi registrada variações entre as variedades. A variedade Crimson o pico ocorreu no décimo dia estendendo-se até o $18^{\circ}$ dia (Figura 1A). No entanto, a 'Charleston' apresentou um pico no $14^{\circ}$ dia (Figura 1B), enquanto as variedades BRS Soleil e Congo apresentaram um pico a partir do $13^{\circ}$ dia (Figura 1C; 1D). Os picos de floração diferenciados apresentados pelas variedades têm sua relevância para a época de introdução de colmeias no cultivo, visando maior pegamento de frutos (Duarte et al., 2015).

O período de emissão de flores femininas para variedade Crimson Select teve início cinco dias após a emissão da primeira flor masculina (Figura 1A). Para as demais variedades o início da emissão de flores femininas ocorreu no $9^{\circ}$ dia após o registro das flores masculinas, e o pico de emissão de flores femininas entre o $12^{\circ}$ ao $22^{\circ}$ dia, diferenciando dos resultados de Duarte et al. (2015) onde o pico de ocorreu do $9^{\circ}$ ao $17^{\circ}$ dia de floração.

Em relação às flores hermafroditas, apenas houve emissão na 'Crimson Select' (Figura 1A), com uma média de 1,28 flores/planta. As outras variedades não apresentaram flores hermafroditas durante o período de floração.

Quanto às flores masculinas, registrou-se maior média na variedade Charleston Gray, seguida da Crimson Select e a menor produção de flores masculina foi registrada pela BRS Soleil (Tabela 1). A variedade Charleston Gray registrou a maior média de flores feminina por planta, seguida da 'Crimson Select'. A variedade BRS Soleil apresentou a menor média de flores feminina por planta (Tabela 1).

Tabela 1. Aspectos da floração de variedades de melancieira (Citrullus lanatus), em cultivo orgânico irrigado, em Juazeiro-BA, em 2018. Fonte: Silva-Júnior et al. (2020).

\begin{tabular}{lccccc}
\hline Variedade & Período de floração (dias) & Razão & \multicolumn{2}{c}{ Número médio de flores } \\
& Masculina & Feminina & sexual & Masculina & Feminina \\
\hline Crimson Select & $18,86 \pm 1,87 \mathrm{C}$ & $7,36 \pm 2,02 \mathrm{~A}$ & 15,56 & $98,07 \pm 24,70 \mathrm{~A}$ & $6,28 \pm 1,86 \mathrm{AB}$ \\
Charleston Gray & $22,43 \pm 2,50 \mathrm{AB}$ & $9,71 \pm 3,56 \mathrm{~A}$ & 15,40 & $115,57 \pm 60,83 \mathrm{~A}$ & $7,50 \pm 5,09 \mathrm{~A}$ \\
Congo & $21,93 \pm 3,12 \mathrm{ABC}$ & $9,00 \pm 4,94 \mathrm{~A}$ & 23,32 & $93,92 \pm 40,78 \mathrm{~A}$ & $4,29 \pm 2,97 \mathrm{AB}$ \\
BRS Soleil & $24,21 \pm 4,33 \mathrm{AB}$ & $8,79 \pm 5,13 \mathrm{~A}$ & 10,11 & $37,86 \pm 15,44 \mathrm{~B}$ & $4,00 \pm 2,32 \mathrm{~B}$ \\
\hline Média Geral & 21,86 & 8,71 & & 86,36 & 5,52 \\
\hline
\end{tabular}

Médias seguidas da mesma letra nas colunas não diferem entre si pelo teste de Tukey a 5\% de probabilidade.

Quanto à razão sexual, a variedade Congo registrou o maior valor $(23,32)$, enquanto que a 'BRS Soleil' apresentou o menor $(10,11)$.

Para o período de floração, observou-se diferença significativa somente para o período de emissão das flores masculinas. A 'BRS Soleil' foi a variedade que emitiu flores por um maior período (24,21 dias), entretanto não diferiu da 'Congo' e da 'Charleston Gray'. A 'Crimson Select' apresentou o menor período de floração (18,86 dias), diferindo da 'BRS Soleil' e 'Congo' (Tabela 1). Por outro lado, a variedade Crimson Select que apresentou o menor período de floração atingiu a segunda maior média para a produção de flores masculina, porém para as flores feminina não houve diferença entre as variedades Congo e Charleston Gray.

A análise referente à viabilidade polínica com os corantes carmim acético e lugol para as variedades de melancieira é expressa na Tabela 2. Para o carmim acético, em todos os horários as quatro variedades apresentaram uma ótima viabilidade com percentuais acima de $87 \%$. No intervalo das $8 \mathrm{~h}$ não foi registrada diferença significativa entre as variedades, com média geral de $90,22 \%$. No intervalo das $11 \mathrm{~h}$, quando foram registrados os menores percentuais de viabilidade, também não foi registrada diferença entre as variedades, o mesmo ocorrendo para o intervalo das 14h (Tabela 2). 
Tabela 2. Percentuais de viabilidade polínica de variedades de (Citrullus lanatus), com dois corantes celulares, em diferentes horários de avaliação, sob cultivo orgânico irrigado, Juazeiro-BA, em 2018. Fonte: Silva-Júnior et al. (2020).

\begin{tabular}{|c|c|c|c|}
\hline \multirow{2}{*}{ Variedade } & \multicolumn{3}{|c|}{ Horário } \\
\hline & $8 \mathrm{~h}$ & $11 \mathrm{~h}$ & $14 \mathrm{~h}$ \\
\hline & \multicolumn{3}{|c|}{ Carmim acético (\%) } \\
\hline Crimson Select & $91,00 \mathrm{Aa}$ & $82,44 \mathrm{Aa}$ & $90,44 \mathrm{Aa}$ \\
\hline Congo & $90,67 \mathrm{Aa}$ & $88,33 \mathrm{Aa}$ & $95,22 \mathrm{Aa}$ \\
\hline Charleston Gray & $91,67 \mathrm{Aa}$ & $89,78 \mathrm{Aa}$ & $94,67 \mathrm{Aa}$ \\
\hline BRS Soleil & $87,55 \mathrm{Aa}$ & $88,44 \mathrm{Aa}$ & $91,00 \mathrm{Aa}$ \\
\hline Média Geral & \multicolumn{2}{|r|}{ Lugol (\%) } & 92,83 \\
\hline Crimson Select & $98,44 \mathrm{Aa}$ & $93,11 \mathrm{Aa}$ & $89,89 \mathrm{Aa}$ \\
\hline Congo & $96,22 \mathrm{Aa}$ & $95,89 \mathrm{Aa}$ & $78,67 \mathrm{Ab}$ \\
\hline Charleston Gray & $94,22 \mathrm{Aa}$ & $93,67 \mathrm{Aa}$ & $89,89 \mathrm{Aa}$ \\
\hline BRS Soleil & $92,89 \mathrm{Aa}$ & $91,78 \mathrm{Aa}$ & $90,55 \mathrm{Aa}$ \\
\hline Média Geral & 95,44 & 93,61 & 87,25 \\
\hline
\end{tabular}

Médias seguidas da mesma letra maiúscula na linha e minúscula na coluna não diferem entre si pelo Teste de Tukey a 5\% de significância.

Avaliando somente os horários, não se observou diferença significativa entre as variedades, semelhante ao registrado ao carmim acético. Entretanto, quando observada a variedade Congo vemos que esta apresentou uma variação significativa durante o dia, com redução da viabilidade significativa as $14 \mathrm{~h}$ (Tabela 2 ). De modo geral os maiores percentuais de viabilidade registrado com corante lugol ocorreram às $8 \mathrm{~h}$ $(95,44 \%)$, seguido das $11 \mathrm{~h}(93,61 \%)$ e das $14 \mathrm{~h}$ $(87,25 \%)$, apresentando o maior percentual médio por horário, em seguida, o período de $11 \mathrm{~h}$ $(93,61 \%)$, demonstrando o percentual médio, o horário de $14 \mathrm{~h}(87,25 \%)$ apresentando menor média geral.

$\mathrm{O}$ volume de néctar produzido por ambos os tipos florais além de reduzido foi bastante semelhante. Nos horários avaliados registrou-se diferença significativa entre as variedades, demostrando a maior média de volume do néctar para as flores masculinas em todos os horários (Tabela 3).

Tabela 3. Volume $(\mu \mathrm{L})$ de néctar dos tipos florais das variedades de melancieira (Citrullus lanatus), em cultivo orgânico irrigado, Juazeiro-BA, em 2018. Fonte: Silva-Júnior et al. (2020).

\begin{tabular}{lcccc}
\hline Variedade & \multicolumn{4}{c}{ Horário } \\
\hline Crimson Select & $\mathbf{8 h}$ & $\mathbf{1 1 h}$ & $\mathbf{1 4 h}$ & $\mathbf{1 7} \mathbf{~ h}$ \\
Feminina & & & & \\
Masculina & $2,71 \mathrm{~A}$ & $1,55 \mathrm{~B}$ & $1,86 \mathrm{~A}$ & $1,49 \mathrm{~A}$ \\
\hline Congo & $3,80 \mathrm{~A}$ & $1,83 \mathrm{~A}$ & $2,65 \mathrm{~A}$ & $2,64 \mathrm{~A}$ \\
Feminina & $1,75 \mathrm{~B}$ & $1,31 \mathrm{~B}$ & $0,99 \mathrm{~B}$ & $1,50 \mathrm{~A}$ \\
Masculina & $4,36 \mathrm{~A}$ & $3,86 \mathrm{~A}$ & $2,77 \mathrm{~A}$ & $2,88 \mathrm{~A}$ \\
\hline Charleston Gray & & & & \\
Feminina & $1,94 \mathrm{~B}$ & $1,82 \mathrm{~A}$ & $1,26 \mathrm{~A}$ & $1,02 \mathrm{~B}$ \\
Masculina & $3,38 \mathrm{~A}$ & $1,42 \mathrm{~A}$ & $1,51 \mathrm{~A}$ & $3,10 \mathrm{~A}$ \\
\hline BRS Soleil & & & & \\
Feminina & $2,23 \mathrm{~A}$ & $1,67 \mathrm{~B}$ & $2,04 \mathrm{~A}$ & $2,11 \mathrm{~A}$ \\
Masculina & $3,31 \mathrm{~A}$ & $3,22 \mathrm{~A}$ & $3,10 \mathrm{~A}$ & $2,58 \mathrm{~A}$ \\
\hline
\end{tabular}

Médias seguidas da mesma letra na coluna não diferem entre si pelo Teste de Tukey a 5\% de significância.

Relacionando o volume médio de néctar produzidor pelos tipos florais, podemos observar na Tabela 4 o horário de $8 \mathrm{~h}$ apresentou maior média de produção de néctar não diferindo significativamente entre as flores masculina e feminina, por outro lado o período de $11 \mathrm{~h}$ e $17 \mathrm{~h}$ as variedades apresentaram diferença significativa na produção de néctar, sendo que as flores masculinas exibiram a maior média em relação as flores femininas.

Tabela 4. Volume ( $\mu \mathrm{L})$ de néctar dos tipos florais das variedades de melancieira (Citrullus lanatus), em cultivo orgânico irrigado, Juazeiro-BA, em 2018. Fonte: Silva-Júnior et al. (2020).

\begin{tabular}{ccccc}
\hline \multirow{2}{*}{ Sexo da flor } & \multicolumn{4}{c}{ Horário } \\
& $8 \mathrm{~h}$ & $11 \mathrm{~h}$ & $14 \mathrm{~h}$ & $17 \mathrm{~h}$ \\
\hline
\end{tabular}




$\begin{array}{lllll}\text { Feminina } & 2,16 \mathrm{~A} & 1,49 \mathrm{~B} & 1,54 \mathrm{~B} & 1,54 \mathrm{~B} \\ \text { Masculina } & 3,71 \mathrm{~A} & 2,68 \mathrm{~A} & 2,51 \mathrm{~A} & 2,79 \mathrm{~A}\end{array}$

Médias seguidas da mesma letra na coluna não diferem entre si pelo Teste de Tukey a $5 \%$ de significância.

A reposição contínua do néctar permite a visitação dos polinizadores por um período mais longo e favorece a transferência do pólen. Foi observado, para outras espécies de plantas, que a disponibilidade ininterrupta de néctar pode garantir a retenção de polinizadores (Cobra et al., 2017). Contudo, observou-se uma redução na produção do néctar ao longo do dia, em ambos os tipos florais da melancieira, sugerindo que, durante o dia, pode ocorrer uma maior concentração de polinizadores em horário de maior disponibilidade do recurso floral.

Observando a Tabela 5, a produção média volume de néctar total para todas as flores feminina das cultivares não apresentaram diferença significativa a $5 \%$ de probabilidade. Em contrapartida, as flores masculinas apresentaram diferença significativa com a variedade Congo apresentando a maior média do volume diferindo da 'Crimson Select' e 'BRS Soleil', no entanto a 'Charleston Gray' apresentou a menor média de volume produzido para as flores masculinas (Tabela 5).

Tabela 5. Volume de néctar $(\mu \mathrm{L})$ dos tipos florais das variedades de melancieira (Citrullus lanatus), em cultivo orgânico irrigado, Juazeiro-BA, 2018. Fonte: Silva-Júnior et al. (2020).

\begin{tabular}{lcc}
\hline Variedade & Feminina & Masculina \\
\hline Crimson Select & $1,90 \mathrm{~A}$ & $2,73 \mathrm{AB}$ \\
Congo & $1,39 \mathrm{~A}$ & $3,47 \mathrm{~A}$ \\
Charleston Gray & $1,41 \mathrm{~A}$ & $2,45 \mathrm{~B}$ \\
BRS Soleil & $2,01 \mathrm{~A}$ & $3,05 \mathrm{AB}$ \\
\hline
\end{tabular}

Médias seguidas da mesma letra na coluna não diferem entre si pelo Teste de Tukey a 5\% de significância.

Como enfatizado, a oferta de néctar é um recurso floral muito importante para a polinização. Se, além do pólen, este recurso for disponibilizado pelas flores masculinas, a atratividade aos polinizadores pode aumentar ainda mais, pois a proporção do tipo floral masculino é maior do que o tipo feminino, como observado anteriormente (Figura 1; Tabela 1), proporcionando maior fluxo de pólen entre plantas no cultivo (Duarte et al., 2015) e maior chance de sucesso da polinização.

Em relação à produção de fruto/planta, a variedade Charleston Gray obteve a maior média de produção de frutos (Tabela 6), seguida da 'Crimson Select', sendo as variedades que apresentaram maior razão sexual flor masculina:feminina e maior período de floração. A menor média foi da variedade 'BRS Soleil'.

Tabela 6. Média de frutos por planta das variedades de melancieira (Citrullus lanatus), em cultivo orgânico irrigado, Juazeiro-BA, 2018. Fonte: Silva-Júnior et al. (2020).

\begin{tabular}{lc}
\hline Variedade & Fruto / Planta \\
\hline Crimson Select & 2,2 \\
Congo & 1,4 \\
Charleston Gray & 2,5 \\
BRS Soleil & 1,0 \\
\hline
\end{tabular}

\section{Conclusões}

As variedades em estudo apresentam diferenças quanto ao período floral, sendo a mais precoce a 'BRS Soleil', com a maior razão sexual para a variedade Congo.

Os grãos de pólen mostram-se viáveis e o estigma receptivo durante todo o período de avaliação.

A disponibilidade de néctar foi reduzida, acentuadamente, com o decorrer do dia, com maior volume nas flores masculinas.

A variedade 'Charleston Gray' apresentou maior média de produção de frutos, o que pressupõe uma relação com a disponibilidade de flores aos visitantes.

\section{Agradecimentos}

À Fundação de Amparo à Pesquisa do Estado da Bahia e Conselho Nacional de Desenvolvimento Científico e Tecnológico pela concessão de bolsas de pesquisa para os três primeiros autores.

\section{Referências}

Ajuru, M. G.; Okoli, B. E. 2013. The Morphological Characterization of the Melon Species in the Family Cucurbitaceae Juss, and their Utilization in Nigeria. Int. J. of Modern Botany, 3, 2, 15-19.

Alencar, L. C. 2013. Efeitos de abelhas na frutificação e qualidade de melancia (cv. Crimson Sweet) na região Central do estado do Piauí. Tese de Doutorado, Universidade Estadual Paulista, Jaboticabal, São Paulo, Brasil. 52p.

Cobra, S. S. O.; Silva, C. A.; Krause, W.; Lage, L. A. 2017. Availability of floral resources in yellow passion fruit cultivars. Comunicata Scientiae, 8, 4, 555-561.

Duarte, P. M.; Siqueira, K. M. M.; Silva, N. C.; Silva, G. B. S.; Gomes, I. L. S. 2015. Floração e morfologia floral de variedades de melancieira em Juazeiro-BA. R. V. de Agroec. e Des. Sustentável, 10, 3, 72-76. 
Embrapa. 2015. Dados Meteorológicos, Estação Agrometeorológica de Mandacarú 19752014, Juazeiro-BA. Disponível em: http://www.cpatsa.embrapa.br:8080/servicos /dadosmet/cem-anual.html. Acesso em: 08 novembro 2019.

Fao. Food and Agriculture Organization of the United Nations Statistics Division. Disponível em: http://www.fao.org/faostat/en/\#data/QC. Acesso em: 08 novembro 2019.

Free, J. B. 1993. Insect pollination of crops. London: Academic Press, Second Edition.

Ferreira, D. F. 2011. Sisvar: a computer statistical analysis system. Ciência e Agrotecnologia, 35, 6, 1039-1042.

Instituto Brasileiro de Geografia e Estatística (IBGE). 2016. Produção Agrícola Municipal: Culturas temporárias e permanentes 2016. Rio de Janeiro: IBGE, 2016. Disponível em: https://www.ibge.gov.br/estatisticas/economi cas/agricultura-e-pecuaria/9117-producaoagricola-municipal-culturas-temporarias-epermanentes. Acesso em: 28 março 2020.

Kearns, C. A.; Inouye, D. W. 1993. Techniques for pollination biologists. University Press of Colorado, Colorado.

Kiill, L. H. P.; Siqueira, K. M. M.; Coelho, M. S.; Silva, T. A.; Gama, D. R. S.; Araújo, D. C. S.; Pereira Neto, J. 2014. Frequency and foraging behavior of Apis mellifera in two melon hybrids in Juazeiro, state of Bahia, Brazil. Anais da Academia Brasileira de Ciência, 86, 4, 2049-2055.

Potts, S. G.; Biesmeijer, J. C.; Kremen, C.; Neumann, P.; Schweiger, O.; Kunin, W. E. 2010. Global pollinator declines: trends, impacts and drivers. Trends Ecol. Evol., 25, 6, 345-353.

Potts, S. G.; Imperatriz-Fonseca, V.; Ngo, H. et al. 2016. Safeguarding pollinators and their values to human well-being. Nature, 540, 220-229.

Pagliarini, M. S., Pozzobon, M. T. 2004. Meiose em vegetais: um enfoque para a caracterização de germoplasma. Anais do II Curso de citogenética aplicada a recursos vegetais. pp. 24-41.

Ramos, A. R. P.; Dias, R. C. S.; Aragão, C. A. 2009. Densidades de produtividade e qualidade de frutos de melancia. Horticultura Brasileira, 27, 4, 560-564.

Reyes-Carrillo, M. C. J. L.; Cano-Rios, P.; Camberos, U. N. 2009. Período óptimo de polinización del melón con abejas melíferas (Apis mellifera L.). Agri. Téc. en México, 35, 4, 371-378.

Siqueira, K. M. M; Kiill, L. H. P.; Gama, D. R. S.; Araújo, D. C. S.; Coelho, M. S. 2011. Comparação do padrão de floração e de visitação do melo do tipo amarelo em Juazeiro-BA. Rev. Bras. de Frut., 33, 1, 473 478.

Souza, F. F.; Dias, R. C. S. BRS Soleil e BRS Kuarah: melancias de polpa amarela. Petrolina: Embrapa Semiárido, 2011. Np. 1 Folder. Disponível em: https://ainfo.cnptia.embrapa.br/digital/bitstre am/item/133322/1/ID-35733.pdf. Acesso em: 08 outubro 2019.

Zeisler, M. 1938. Über die Abgrenzung der eigentlichen Narbenfläche mit Hilfe von Reaktionen. Beiheft Botanischer Zentralblatt, 58, 308-318. 